\title{
Bee and wasp stings of the eye. Retained intralenticular wasp sting: a case report
}

\author{
M. GILBOA, M. GDAL-ON, AND S. ZONIS \\ From the Eye Department, Rambam Medical Center, Aba Khoushy School of Medicine, Haifa, Israel
}

SUMMARY Two different stages should be considered in the management of bee and wasp stings to the eye. The first is the acute stage of activity of the specific insect venom on the structures of the eye. The reaction of the eye to the particular insult is considered here in regard to the anterior and posterior segments of the eye. The second stage is that of the retained intraocular foreign body, the inert sting. Little is known about the reaction of the eye to the presence of the chitinous sting and its effect on the structures of the eye. We report a follow-up study of a sting retained for 28 years, and emphasise the benign and quiescent course of the case. Guidelines for treatment and management in such cases are described.

'Damage to the eye caused by insects is frequent. Their sting may cause considerable reactions and leucomata of the eye' (Van Horn, 1948). The list of foreign bodies which may enter the eye is endless. Some of these are typical and common to agricultural surroundings. Insects - their wings, legs, spines, or stings-are common intraocular foreign bodies in these surroundings as well as in some tropical regions. Occasionally stinging insects introduce into the eye part or parts of their bodies, as do wasps and bees (Duke-Elder, 1940).

We discuss here the management and treatment of such foreign bodies and report on a long-term follow-up study of retained intraocular wasp sting.

\section{Case history}

A 48-year-old man was examined routinely in our department for the purpose of changing his glasses. On examination his visual acuity was found to be: right eye $6 / 9$, with correction $-0.5 \mathrm{sph}$., $-0.5 \mathrm{cyl} .140^{\circ}$; left eye $6 / 6$, with correction $-1 \cdot 5$ sph., -0.5 cyl. $90^{\circ}$. Intraocular tension was $14.5 \mathrm{mmHg}$ in both eyes. His left eye was quiet, refracting surfaces were clear, and there were perfect fundi. In the centre of the cornea of his right eye a fine scar was found, and in the centre of the lens in front of it an insect sting was seen protruding into the anterior chamber. The foreign body appeared to resemble a needle, and the area of penetration was a circular opacity, confined to the anterior lens capsule (Fig. 1). No signs of iritis were found. The pupil was round and

Address for reprints: $\operatorname{Dr}$ M. Gilboa, Éye Department, Rambam Medical Center, Aba Khoushy School of Medicine, Haifa, Israel

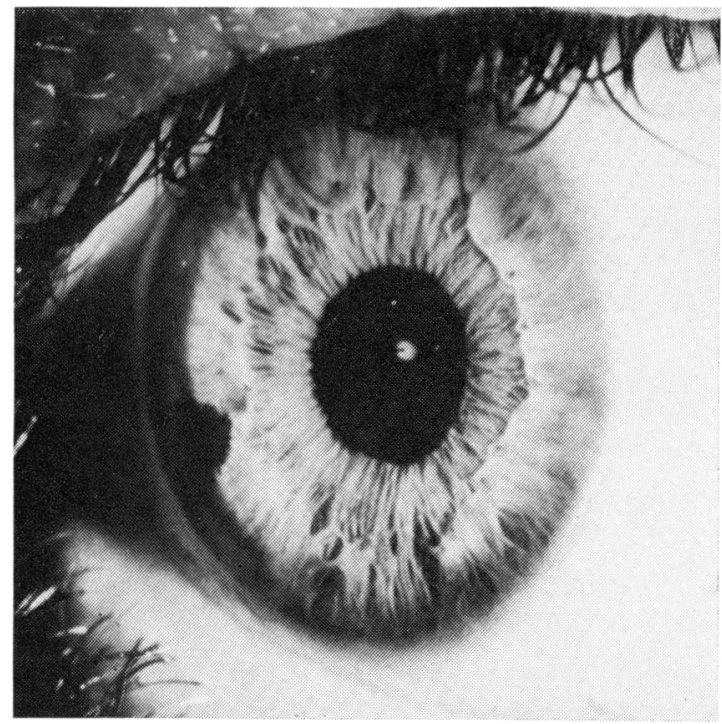

Fig. 1 Retained intralenticular wasp sting. Embedded sting in the centre of the lens protruding into the anterior chamber

responsive to light. The lens was clear in all its other parts, the fundus was normal, and no other signs of disease were seen.

The patient said he remembered having been hit and stung by a wasp on his upper right eyelid 28 years previously. This resulted in so severe a reaction that the patient was in hospital for several days.

From records made at the time which we received from the hospital we obtained the following additional information. The patient was in hospital from 31 July to 8 August 1948 suffering from oedema of 
the conjunctiva as a result of a wasp sting in the right eye. Round the sting was a white corneal infiltration and a lack of epithelial covering.

After several days in hospital a marked improvement was noted, with regression of the oedema and recovery of the epithelium. On discharge from hospital some ciliary injection and a slight infiltration of the right cornea remained. In this condition the patient was referred to the outpatient treatment.

No mention was made in the records of the sting having remained embedded in the lens. In subsequent years the sting did not cause any inflammation or subjective complaints by the patient except for a slight lessening of visual acuity in the affected eye.

\section{Discussion}

The frequency of wasp and bee stings and the species of wasp or bee involved depend on the geographical location and the season of the year. In the act of stinging, these insects introduce two bodily components into the eye: the chitinose sting and the specific venom which the sting contains. The venom acts as a toxic agent, and the sting itself has a mechanically damaging effect on the structures of the eye (Grant, 1962; Bucherl and Buckley, 1971).

Bee and wasp stings of the eye have been well discussed by Lewin and Guillery (1913), Young (1931), and Kranning (1955). The sting, a modified ovipositor in the female, usually lies in the abdomen and is typically provided with toothed lancets and poison glands containing venom. Its toxic action is presumed to be due to several biological amines (Welsh, 1964; Owen, 1971). This mixture of compounds acts as a potent protoplasmic poison, which produces a violently painful oedematous reaction, local as well as general. Several active components in this mixture have been found, and the specific composition of the venom is known to differ in the bee and the wasp. Some biologically active components which have been isolated in bee venom are neurotoxin, haemolitin, mellitin, hyaluronidase, phospholipase $\mathrm{A}$, and histamine. Wasp venom contains acetylcholine in addition. Wasp stings appear to be more painful and more serious in nature than bee stings. From the practical and clinical points of view, however, bee and wasp stings may be considered together.

\section{Reaction of the eye}

\section{ANTERIOR SEGMENT}

The cornea. The most serious reaction of the anterior segment has been encountered in cases in which the sting entered the cornea. The victim suffers much pain and photophobia associated with clouding and swelling of the cornea itself. Iritis, hypopyon, and mixed conjunctival and ciliary injection develop. Typically, in wasp stings bullous keratitis has been known to persist for many months. Characteristically, a striate keratitis and pathognomonically, a fine network of ridges in the corneal epithelium appear surrounding the retained sting. During the height of the reaction the cornea may become heavily infiltrated at the site of the sting. Histologically, necrosis of cells and a large collection of leucocytes are to be found in the immediate neighbourhood of the sting or at the place of inoculation of the venom. Thereafter the inflammatory reaction gradually subsides. However, the area of the cornea surrounding the sting commonly remains permanently clouded and vascularised. Gradual complete clearing and recovery of normal vision are to be expected (Khachaturova, 1960) even though the sting remains in the cornea. Damage to the eye, specifically to the cornea, results in an irregularity of the corneal surface which may require an astigmatic correction to improve vision, as is seen in our case.

The iris. The iris shows great vasodilatation, with several haemorrhages and leucocytic infiltration, but no necrosis.

The lens. The lens has been known to develop small grey opacities on the anterior surface, even when not mechanically injured by the sting. Anterior polar cataract may appear. Some degeneration of the epithelium of the lens capsule has been reported, with accumulation of fluid between the capsule and the lens substance, followed by proliferation of the intact epithelium (Huwald, 1904).

\section{POSTERIOR SEGMENT}

There are some reports of possible neurotoxic effects on the retina and the optic nerve, though it is odd that posterior segment complications have usually not been associated with stings to the eye specifically but to the lids or elsewhere in the head. Optic atrophy and papillitis secondary to bee sting have been described (Walsh and Hoyt, 1969; Goldstein and Woltman, 1960). Papilloedema of 1 dioptre and much retinal venous engorgement with normal visual acuity have been observed 9 days after bee stings (Goldstein and Rucker, 1964). Retrobulbar neuritis has been described following wasp stings (Konstas and Nikolinakos, 1965). These severe reactions seem to be related to the venoms carried with the sting and not to the sting itself.

\section{Clinical and experimental studies}

From clinical observations and experiments on animals it is evident that we must consider two 
different effects on the eye: the reaction to the specific venom and the effect of the chitinous sting. From experimental studies on rabbits (Strobel, 1931) it has been concluded that, once the toxic material is inactivated from the bee or wasp sting, it becomes completely inert and can be retained in the cornea or anterior chamber without trouble. It has been shown that the venom is responsible for the severe inflammatory reactions, that the severity depends on the amount of venom, and that it is unimportant whether or not the sting itself remains embedded in the eye. As to the presence of the sting in the eye over a prolonged period, there are few relevant reports and almost no follow-up studies. But one case followed up for 21 years has been described (Strobel, 1950), in which a bee sting was retained within the cornea, protruding into the anterior chamber, with no signs of inflammation. In our case the follow-up was for more than 28 years without any signs of inflammatory activity.

\section{Treatment}

\section{ACUTE STAGE}

As soon as possible after the patient is stung therapeutic action must be taken against the activity of the venom. Some therapeutic suggestions have been made. Repeated paracentesis may be employed in cases in which the sting has entered the anterior chamber (Strobel, 1950). However, it seems that the correct use of modern anti-inflammatory medical treatment will control the inflammation and will prevent possible later complications. Use of antibiotics, antihistamines, and local and systemic corticosteroids is imperative according to the severity of the inflammation in each particular case.

\section{RETAINED STING}

The presence of the sting as a retained intraocular foreign body is a problem for the clinician. Injury as a result of injudicious and awkward attempts at its removal may cause permanent damage to vision and even occasionally lead to the loss of the eye. If the only sequela of being stung is retention of the inert sting, no surgical intervention is advisable.

\section{References}

Bucherl, W., and Buckley, E. (1971). Venomous Animals and their Venoms, Vol. 2, p. 3.

Duke-Elder, S. (1940). In System of Ophthalmology, ed. W. S. Duke-Elder, Vol. 14, pp. 551, 1204. Henry Kimpton: London.

Goldstein, S., and Rucker, G. (1964). Journal of the American Medical Association, 50, 188.

Goldstein, S., and Woltman, J. (1960). Journal of the American Medical Association, 46, 173.

Grant, A. (1962). Toxicology of the Eye. Springfield.

Huwald, D. (1904). Albrecht von Graefes Archiv für Ophthalmologie, 59, 46.

Khachaturova, N. K. (1960). Vestnik Oftalmologii, 73, 17.

Konstas, P., and Nikolinakos, G. (1965). Archeia Hygieinis, 14, 144.

Kranning, H. D. (1955). Klinische Monatsblätter für Augenheilkunde, 1, 126.

Lewin, L., and Guillery, H. (1913). Die Wirkungen von Arzneimitteln und Giften auf das Auge, 2 ed. Berlin.

Owen, A. (1971). Experientia, 27, 541.

Strobel, G. (1931). Klinische Monatsblätter für Augenheilkunde, 86, 657.

Strobel, G. (1950). Ophthalmologica, 120, 16.

Van Hoorn, N. (1948). Nederlands Tijdschrift voor Geneeskunde, 4, 3748.

Walsh, F. B., and Hoyt, W. F. (1969). Clinical Neuroophthalmology, 3rd ed. Williams \& Wilkins: Baltimore.

Welsh, I. (1964). Annual Review of Pharmacology, 4, 293.

Young, C. A. (1931). American Journal of Ophthalmology 14, 208. 